\title{
Influence of Nanoxides on Diffusivity and Solubility of Hydrogen in Pd-based alloys
}

\author{
Tabatta Regina de Brito Martins ${ }^{a} *$, Viviane Monteiro Azambuja ${ }^{b}$, Dilson Silva dos Santos ${ }^{a, c}$, Sérgio
}

Souto Maior Tavares ${ }^{d}$

aPrograma de Engenharia da Nanotecnologia, Universidade Federal do Rio de Janeiro - UFRJ, Rio de Janeiro, RJ, Brazil

${ }^{b}$ Instituto Federal de Educação Ciência e Tecnologia do Espírito Santo - IFES, Vitória, ES, Brazil

${ }^{c}$ Departmento de Engenharia Metalúrgica e de Materiais, Universidade Federal do Rio de Janeiro UFRJ, Rio de Janeiro, RJ, Brazil

${ }^{d}$ Departamento de Engenharia Mecânica, Universidade Federal Fluminense - UFF, Niterói, Rio de Janeiro, Brazil

Received: May 01, 2017; Revised: October 23, 2017; Accepted: November 27, 2017

\begin{abstract}
The hydrogen interaction in palladium alloys with addition of $\mathrm{Ce}, \mathrm{Zr}$ and $\mathrm{Y}$ was studied. These alloys are produced by arc-melting and then cold rolled into thin foils. Heat treatment at $800^{\circ} \mathrm{C}$ for $24 \mathrm{~h}$ in air atmosphere is applied to induce internal oxidation. Hydrogen permeation tests and TDS (Thermal Desorption Spectroscopy) are carried out to evaluate hydrogen interaction with three different microstructures which can be characterized by dislocations, substitutional atoms and nanoxides. For alloys argon annealed, $\mathrm{Ce}$ is the element that delays the most hydrogen diffusion, followed by $\mathrm{Zr}$ and Y. However alloys with yttrium nanoxides exhibit the highest solubility and the smallest diffusivity due to their small size, spherical shape and dispersion throughout the matrix. Analyzing TDS curves, it is shown that nanoxides are irreversible traps that improve hydrogen stored on palladium alloys. Dislocations and impurity atom on solid solution have little binding energy that detraps hydrogen at smaller temperatures.
\end{abstract}

Keywords: nanoxides, internally oxidation, palladium, diffusivity of hydrogen, solubility of hydrogen.

\section{Introduction}

Pd alloys are a noble and costly metal; however, they have special characteristics with regard to hydrogen, such as: excellent kinetics of adsorption and absorption of hydrogen, durability as a function of hydrogen loading and unloading, as well as good mechanical resistance when there is formation of the hydride phase. Pd-H system has many engineering applications, such as fuel cells, filters and hydrogen separators; can also be used as hydrogen storage tanks and catalysts. Thus Pd alloys are so studied by science and engineering ${ }^{1,2}$. In addition, the palladium alloys are widely used to understand the interaction of hydrogen with the crystalline defects, precisely because of all these presented properties.

Microstructure plays such an important role on hydrogen diffusion and solubility. Dislocations, vacancies, grain boundary, substitutional and interstitial atoms, and interfaces induce distortions and high energy fields on crystalline structure. These defects are preferable sites to hydrogen trapping. The nature of this interaction between hydrogen and a given microstructure defines whether a trap is reversible or irreversible ${ }^{3}$. Despite the hydrogen diffusion through the lattice is independent of the trap sites, this amount delays

*e-mail: tabattabrito@id.uff.br hydrogen permeation, because the permeation only starts after all trappings are filled. Therefore the hydrogen permeation is delayed because hydrogen trap sites on matrix. Cao and coworkers ${ }^{10}$ investigated the relationship between amount of cold work, dislocation density and hydrogen diffusion, they concluded that when increasing the amount of deformation in palladium, the dislocation density also increased, and hydrogen permeation in palladium is delayed even more.

$\mathrm{PdX}$ alloys where $\mathrm{X}$ is an element which interacts strongly with oxygen (such as $\mathrm{Y}, \mathrm{Zr}, \mathrm{Ce}, \mathrm{Al}, \mathrm{Cu}$ ) can be heat treated to obtain nanoxides on Pd lattice. This occurs when these alloys are exposed to an oxidizing atmosphere at high temperature for extended treatment times, sufficient to permit the oxygen diffusion through the metallic matrix. Such oxides promote an increase in hydrogen solubility as well as improve the mechanical properties of these alloys ${ }^{4-6}$.

In this sense, this paper presents how different microstructures promote drastic changes in the diffusivity and solubility of hydrogen. PdX alloys were arc-melted, cold rolled and heat treated to make three different samples: argon annealed (substitutional atom on Pd lattice), cold worked (combine effect of substitutional atom on Pd lattice and dislocations) and internally oxidized (nanoxides interfaces). X-ray diffraction, SEM (Scanning Electron Microscopy) and 
TEM (Transmission Electron Microscopy) were performed to characterize the samples. Hydrogen permeation tests and TDS (Thermal Desorption Spectroscopy) were carried out to investigate hydrogen interaction with these microstructures. The microstructure with the lowest diffusion coefficient is the internally oxidized. Among the studied PdX alloys, the one containing yttrium oxide is the alloy with the lowest diffusion coefficient, followed by the one with zirconium oxide and the last one containing cerium oxide. This delay in the hydrogen permeation is related to the morphology of the oxides, their size and distribution.

\section{Materials and Experimental Methods}

With the purpose of investigating the interaction between hydrogen and cerium, zirconium or yttrium nanoxides, some $\mathrm{Pd}_{0.97} \mathrm{X}_{0.03}$ alloys were prepared, from the commercial pure elements by arc-melting. Subsequently, all buttons of alloys, with about $15 \mathrm{~mm}$ in diameter, were cold rolled in six passes into a thin foil $(200 \mu \mathrm{m})$ and three different samples of each one were separated, where the first was named $\mathrm{Pd}_{0.97} \mathrm{X}_{0.03} \mathrm{CW}$ (cold worked) and the others were heat treated at $800^{\circ} \mathrm{C}$ per $24 \mathrm{~h}$ under argon and air atmospheres, producing respectively, $\mathrm{Pd}_{0.97} \mathrm{X}_{0.03} \mathrm{AA}$ (argon annealed) and $\mathrm{Pd}_{0.97} \mathrm{X}_{0.03}$ IO (internally oxidized). As Cao and coworkers ${ }^{10}$ demonstrated, the quantity of cold work intervenes on hydrogen diffusion, so that the same amount of cold work was imposed on all alloys studied. Figure 1 shows the sample preparation flowchart. The heat treatment under argon produced alloys without dislocations begotten by cold work, whereas an internal oxidation was performanced due to reactive atmosphere. Therefore, the sample $\mathrm{Pd}_{0.97} \mathrm{X}_{0.03}$ AA allowed studying the effect of a substitutional atom on hydrogen trapping, while $\mathrm{Pd}_{0.97} \mathrm{X}_{0.03} \mathrm{CW}$ let a combined action of a substitutional atom and dislocations. The last sample highlighted the hydrogen interaction only with nanoxides.

Samples of $15 \times 15 \mathrm{~mm}$ dimension were submitted to electrochemical hydrogen permeation tests, at room temperature, using a $0.1 \mathrm{M} \mathrm{NaOH}$ solution as electrolyte as described elsewhere ${ }^{7}$. These tests were undertaken using an electrochemical cell comprising two compartments separated by the sample. In one of them, a constant cathodic current was applied to generate hydrogen at the surface of the metal foil. In the other compartment, a weak anodic potential was applied to oxidize the hydrogen that permeates through the sample. For each sample, two cycles of sorption-desorption were applied to promote the saturation of the trap sites. The cathodic current used was $1 \mathrm{~mA}$.

Before and after permeation tests, the resulting samples were characterized by a X-ray diffraction with the use of Bruker D8 discovery diffractometer which operated with $\mathrm{Cu} \mathrm{K} \alpha$ radiation.

The surface of the alloys was observed by SEM and microanalyses were performed by EDS (Energy Dispersive $\mathrm{X}$-ray Spectrometer). The grain boundaries were visible due to internally oxidation, even without etching. Furthermore, the nanoxides morphology were analyzed by TEM operating at $200 \mathrm{kV}$ and equipped with an energy dispersive X-ray spectrometry for microanalysis (EDS). The disks with 3 $\mathrm{mm}$ in diameter were then carefully polished to a thickness of about $80 \mu \mathrm{m}$. Then specimens were prepared by dual jet electropolishing using a Struers Tenupol-5 electropolisher with an electrolyte composed of 91 vol.\% acetic acid and 9 vol.\% perchloric acid at $15^{\circ} \mathrm{C}$ and a voltage of $20.5 \mathrm{~V}$ against a $\mathrm{Pt}$ counter electrode.

The nature of hydrogen traps in PdY alloys was investigated by thermal desorption spectroscopy (TDS) with heating rate of $10^{\circ} \mathrm{C} / \mathrm{min}$ from the room temperature until $600^{\circ} \mathrm{C}$. Before the tests, electrochemical hydrogen charging was performed from $0.1 \mathrm{M} \mathrm{NaOH}$ solution with $0.3 \mathrm{~A} / \mathrm{cm}^{2}$ during $24 \mathrm{~h}$.

\section{Results and Discussion}

Figure 2 presents $\mathrm{X}$-ray diffraction patterns for $\mathrm{Pd}_{0.97} \mathrm{Y}_{0.03}$ $\mathrm{CW}$ and for $\mathrm{Pd}_{0.97} \mathrm{Y}_{0.03} \mathrm{IO}$. It was observed that the $\mathrm{CW}$ sample presented only peaks due to a palladium face-centered cubic (FCC) structure with yttrium in solid solution. However, for the IO sample, other diffraction peaks were observed. These new peaks were indexed as $\mathrm{Y}_{2} \mathrm{O}_{3}$ and $\mathrm{PdO}$, this last one was really small. Since yttrium has more affinity with oxygen than palladium, there are more pronounced $\mathrm{Y}_{2} \mathrm{O}_{3}$ peaks. The other alloys have $\mathrm{X}$-ray diffraction patterns very similar to these, the only difference is the oxides formed: $\mathrm{CeO}_{2}$ and $\mathrm{ZrO}_{2}$ for $\mathrm{Pd}_{0.97} \mathrm{Ce}_{0.03}$ and $\mathrm{Pd}_{0.97} \mathrm{Zr}_{0.03}$, respectively.

Figure 3 refers to the SEM analysis of the $\mathrm{Pd}_{0.97} \mathrm{Y}_{0.03} \mathrm{IO}$ alloy and some points were chosen to carry out microanalyses

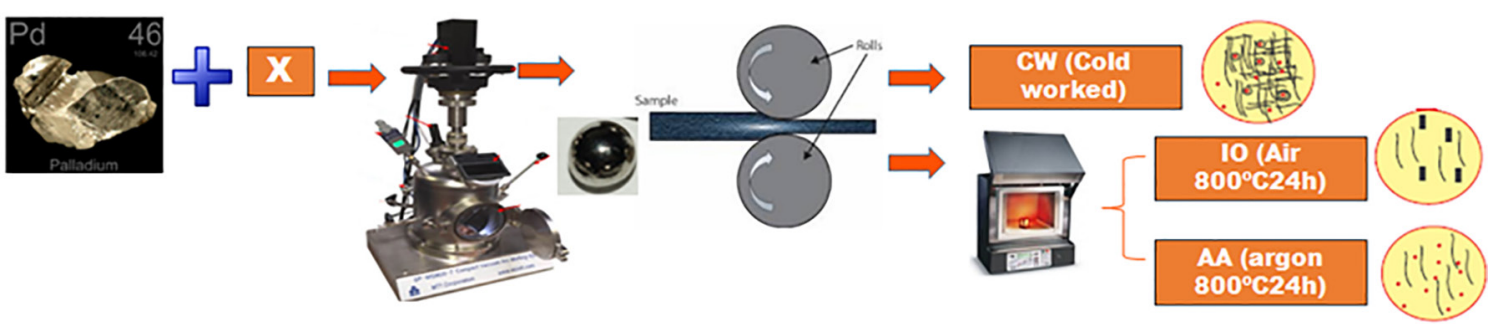

Figure 1. Sample preparation flowchart, where $\mathrm{X}$ is $\mathrm{Ce}, \mathrm{Zr}$ or $\mathrm{Y}$. The heat treatment in air produced internal oxidation (IO condition) and the argon annealing lead to a microstructure with $\mathrm{X}$ atoms in substitutional solution solid. 


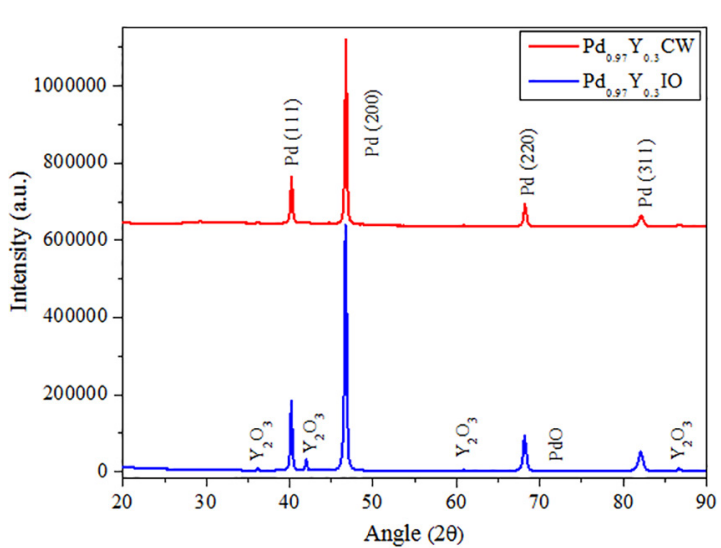

Figure 2. X-ray diffraction patterns for the $\mathrm{Pd}_{0.97} \mathrm{Y}_{0.03}$ alloy: cold worked and oxidized at $800^{\circ} \mathrm{C}$ per $24 \mathrm{~h}$.

by EDS. The same procedure was done for all alloys and made resembling pictures. It can be noticed that point 1 (in grain boundary) presents an oxygen peak and more pronounced yttrium peak when compared with point 2 (on matrix). This difference between point 1 and 2 shows that yttrium oxide forms preferably in grain boundary and a little amount of it remains in solid solution in Pd lattice. Therefore, the internal oxidation was not complete and oxides still stay small enough to be a good hydrogen trap. As it is known when the oxides increase greatly in size they cease to be an efficient trap for hydrogen ${ }^{8}$.
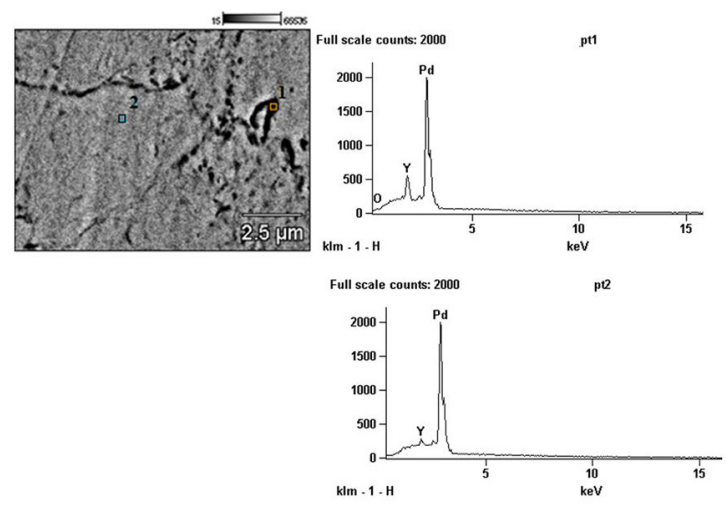

Figure 3. SEM image and EDS for $\mathrm{Pd}_{0.97} \mathrm{Y}_{0.03}$ oxidized at $800^{\circ} \mathrm{C}$ during $24 \mathrm{~h}$.

Figure $4(a-b)$ shows a TEM and SEM photomicrograph of $\mathrm{Pd}_{0.97} \mathrm{Ce}_{0.03}$ IO alloy where the fine acicular ceria precipitates (arrows) of 20-40 $\mathrm{nm}$ in diameter and 1-2 $\mu \mathrm{m}$ in length can be seen ${ }^{6}$. These precipitates exhibited preferential growth directions. Through the diffraction picture it was possible to index the precipitates being $\mathrm{CeO}_{2}$ with crystalline parameter of $\mathrm{a}_{0}=5.41 \AA$, which have a coherence relation with the palladium matrix ${ }^{6}$.

As it can be seen in Figures 5-6, zirconium oxide precipitates in grain boundaries with nanometric size of approximately $15 \mathrm{~nm}$ and almost a square shape (see arrows).

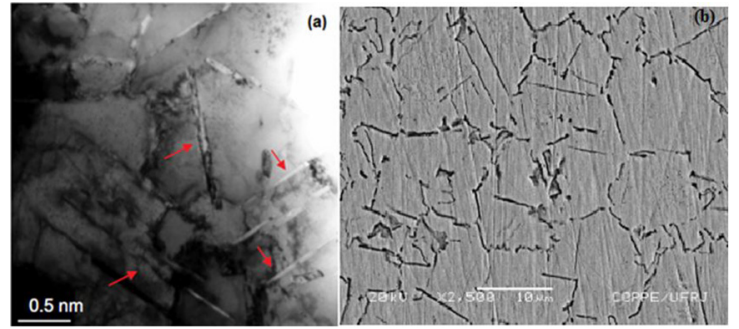

Figure 4. Transmission electron micrograph for $\mathrm{Pd}_{0.97} \mathrm{Ce}_{0.03} \mathrm{IO}^{6}$ (a) and SEM (b).

The zirconium oxide could be indexed as $\mathrm{ZrO}_{1,87}$, with face centered cubic (FCC) structure and lattice parameter $\mathrm{a}_{0}=$ $5.15 \AA$ A. It can also be verified that zirconium oxide, as the cerium oxide, is coherent with the palladium matrix. The yttrium oxides were also investigated (Figure 7) and it was possible observed that their shape is spherical with nanometric size of approximately $10 \mathrm{~nm}$ similar to zirconium oxides, but smaller and spherical.

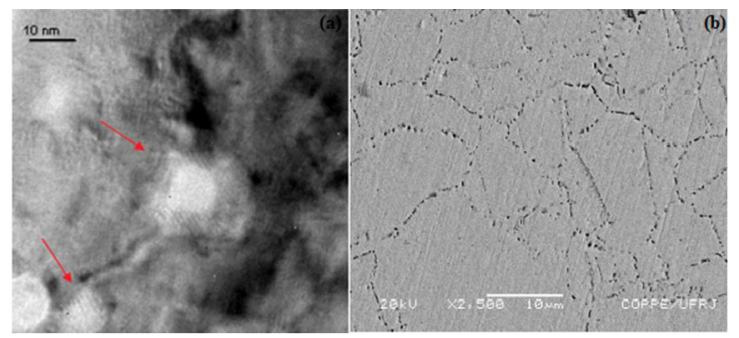

Figure 5. Transmission electron micrograph for $\mathrm{Pd}_{0.97} \mathrm{Zr}_{0.03} \mathrm{IO}$ (a) and SEM (b).

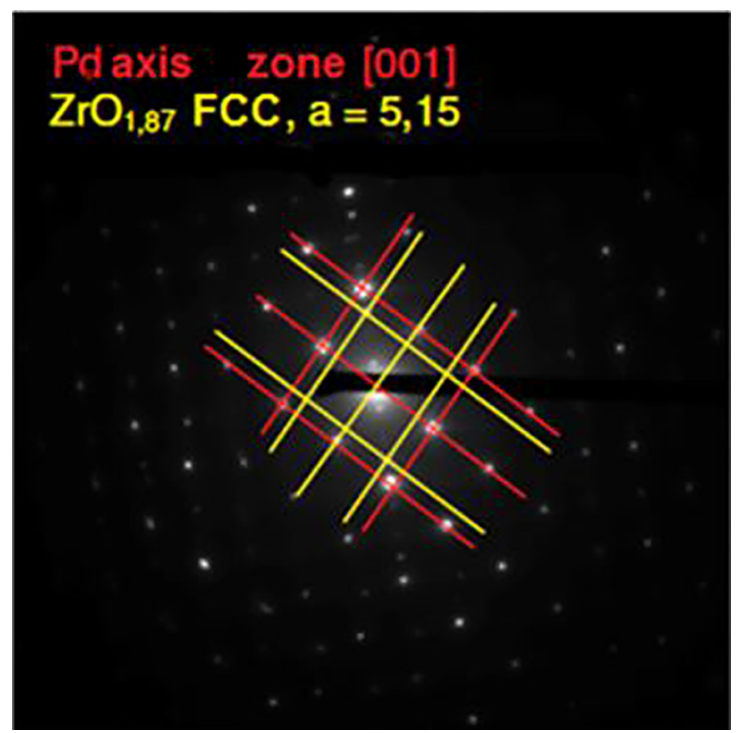

Figure 6. Transmission electron micrograph of selected region electron diffraction pattern for $\mathrm{Pd}_{0.97} \mathrm{Zr}_{0.03} \mathrm{IO}$.

Figure 8 (a-c) shows the hydrogen permeation curves for the $\mathrm{Pd}_{0.97} \mathrm{X}_{0.03}$. The curves were normalized by the value of maximum flux of each curve. In Table 1 the hydrogen 


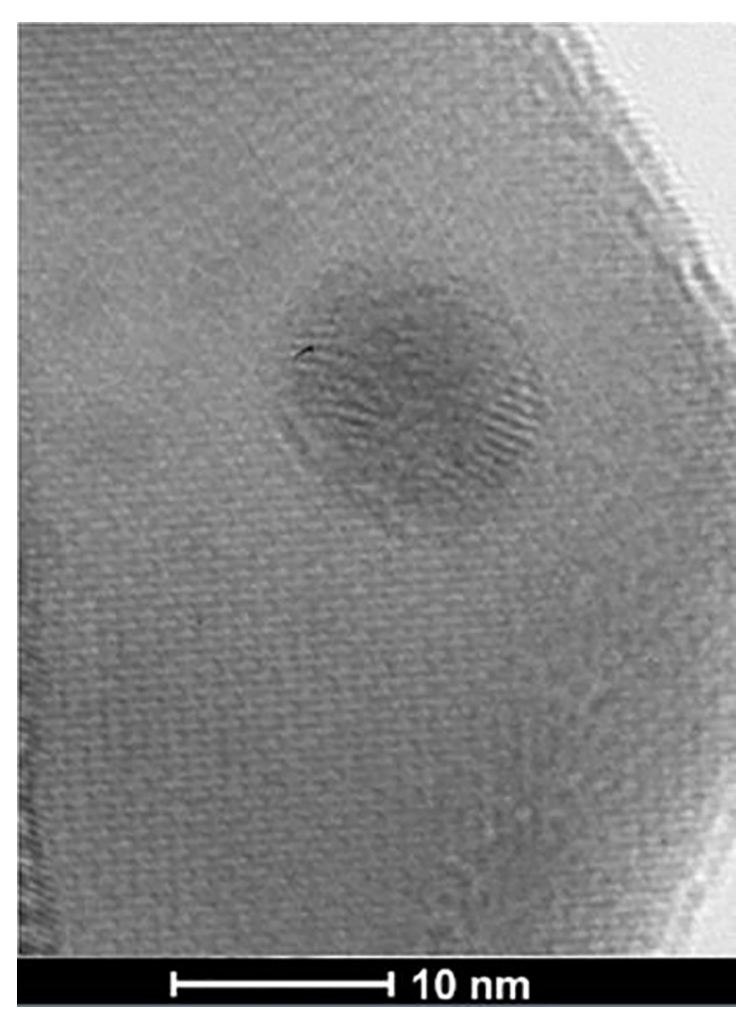

Figure 7. Transmission electron micrograph for $\mathrm{Pd}_{0.97} \mathrm{Y}_{0.03} \mathrm{IO}$, showing a spherical yttrium nanoxide.

permeation parameters of the alloys are compared with those of pure Pd cold worked (CW).

Analyzing Figure 8 and Table 1 data, it can be observed that the addition of $\mathrm{Ce}, \mathrm{Zr}$, or $\mathrm{Y}$ in $\mathrm{Pd}$ lattice induces an increase in the hydrogen permeation time, which represents a decrease on diffusivity of hydrogen. This reduction is less pronounced for the PdX AA than PdX CW or PdX IO. Pure $\mathrm{Pd}$ has $\mathrm{D}_{\text {app }}=5.5 \times 10^{-11} \mathrm{~m}^{2} . \mathrm{s}^{-1}$ and when $\mathrm{Ce}, \mathrm{Zr}$ or $\mathrm{Y}$ are added in Pd lattice, its diffusivity is reduced. For the AA condition, this behavior can be explained by lattice distortion caused by the $\mathrm{X}$ element in solid solution. As $\mathrm{Y}$ possesses an atomic radius closer to $\mathrm{Pd}$, the distortion due to physical nature is smaller than in the case of $\mathrm{Zr}$ and $\mathrm{Ce}$ where the atomic radius is greater than $\mathrm{Pd}$ and $\mathrm{Y}$. This effect was observed for other Pd alloys. Furthermore, other
Table 1. Hydrogen permeation parameters of pure Pd and Pd alloys at $313 \mathrm{~K}$ for cathodic charging current equal to $1 \mathrm{~mA}$.

\begin{tabular}{cccc}
\hline Alloys & $\mathrm{D}_{\text {app }}\left(\mathrm{m}^{2} . \mathrm{s}^{-1}\right)$ & $\begin{array}{c}\mathrm{S}_{\text {app }}(\mathrm{mol} \mathrm{H} \\
\left.\mathrm{m}^{-3}\right)\end{array}$ & $\begin{array}{c}\mathrm{J}_{\text {ce }}(\mathrm{mol} \mathrm{H} \\
\left.\mathrm{m}^{-2} \mathrm{~s}^{-1}\right)\end{array}$ \\
\hline $\mathrm{Pd} \mathrm{CW}$ & $2.6 \times 10^{-11}$ & 1730 & $1.86 \times 10^{-4}$ \\
$\mathrm{Pd}_{0.97} \mathrm{Ce}_{0.03} \mathrm{AA}$ & $3.3 \times 10^{-11}$ & 758 & $1.96 \times 10^{-4}$ \\
$\mathrm{Pd}_{0.97} \mathrm{Ce}_{0.03} \mathrm{CW}$ & $1.9 \times 10^{-11}$ & 1147 & $2.18 \times 10^{-4}$ \\
$\mathrm{Pd}_{0.97} \mathrm{Ce}_{0.03} \mathrm{IO}$ & $6.0 \times 10^{-12}$ & 2863 & $1.95 \times 10^{-4}$ \\
$\mathrm{Pd}_{0.97} \mathrm{Zr}_{0.03} \mathrm{AA}$ & $4.3 \times 10^{-11}$ & 761 & $1.43 \times 10^{-4}$ \\
$\mathrm{Pd}_{0.97} \mathrm{Zr}_{0.03} \mathrm{CW}$ & $1.1 \times 10^{-11}$ & 2081 & $2.19 \times 10^{-4}$ \\
$\mathrm{Pd}_{0.97} \mathrm{Zr}_{0.03} \mathrm{IO}$ & $3.0 \times 10^{-12}$ & 5228 & $2.19 \times 10^{-4}$ \\
$\mathrm{Pd}_{0.97} \mathrm{Y}_{0.03} \mathrm{AA}$ & $5.2 \times 10^{-11}$ & 501 & $2.12 \times 10^{-4}$ \\
$\mathrm{Pd}_{0.97} \mathrm{Y}_{0.03} \mathrm{CW}$ & $6.6 \times 10^{-12}$ & 5280 & $1.76 \times 10^{-4}$ \\
$\mathrm{Pd}_{0.97} \mathrm{Y}_{0.03} \mathrm{IO}$ & $2.5 \times 10^{-12}$ & 7783 & $1.51 \times 10^{-4}$ \\
\hline
\end{tabular}

factors such as valence and stressing must also be considered because different metal valences and an external stress field can improve the hydrogen solubility ${ }^{1,2,9}$.

It was also shown, from Table 1, that cold work decreases hydrogen diffusion coefficient. This could be due to the multiplication of dislocations and generation of vacancies during deformation which trap the hydrogen in a reversible or an irreversible way depending on defect binding energy ${ }^{10}$. Besides that, when element $\mathrm{X}$ in solid solution is combined with cold work, the hydrogen diffusion coefficient is further lowered, in comparison to pure $\mathrm{Pd} \mathrm{CW}\left(\mathrm{D}_{\mathrm{app}}=2.6 \times 10^{-11}\right.$ $\left.\mathrm{m}^{2} \cdot \mathrm{s}^{-1}\right)$. For $\mathrm{X}=\mathrm{Ce}\left(\right.$ alloy $\left.\mathrm{Pd}_{0.97} \mathrm{Ce}_{0.03} \mathrm{CW}\right)$ the decrease of diffusivity was $37 \%$, while for $\mathrm{X}=\mathrm{Y}$ (alloy $\mathrm{Pd}_{0.97} \mathrm{Y}_{0.03} \mathrm{CW}$ ) a decrease of $300 \%$ in the $\mathrm{D}_{\text {app }}$ was measured.

In spite of the difference between atomic rays predominates on hydrogen diffusion coefficient for annealed alloys, the same does not happen for $\mathrm{CW}$ and IO ones. Yttrium is the element that most delayed the hydrogen permeation for $\mathrm{CW}$ and IO conditions; this reduction in the $\mathrm{D}_{\text {app }}$ reaches $96 \%$ and $99 \%$, respectively. For cold worked samples, it happens because bigger atoms are better barriers to dislocations motions, preventing, this way, multiplication of dislocation. Therefore, $\mathrm{Pd}_{0.97} \mathrm{Ce}_{0.03}$ and $\mathrm{Pd}_{0.97} \mathrm{Zr}_{0.03}$ alloys must have lower dislocation densities than $\mathrm{Pd}_{0.97} \mathrm{Y}_{0.03}$.

The diffusivity of hydrogen is inversely proportional to difference atomic rays between $\mathrm{Pd}$ and $\mathrm{X}$ element, for
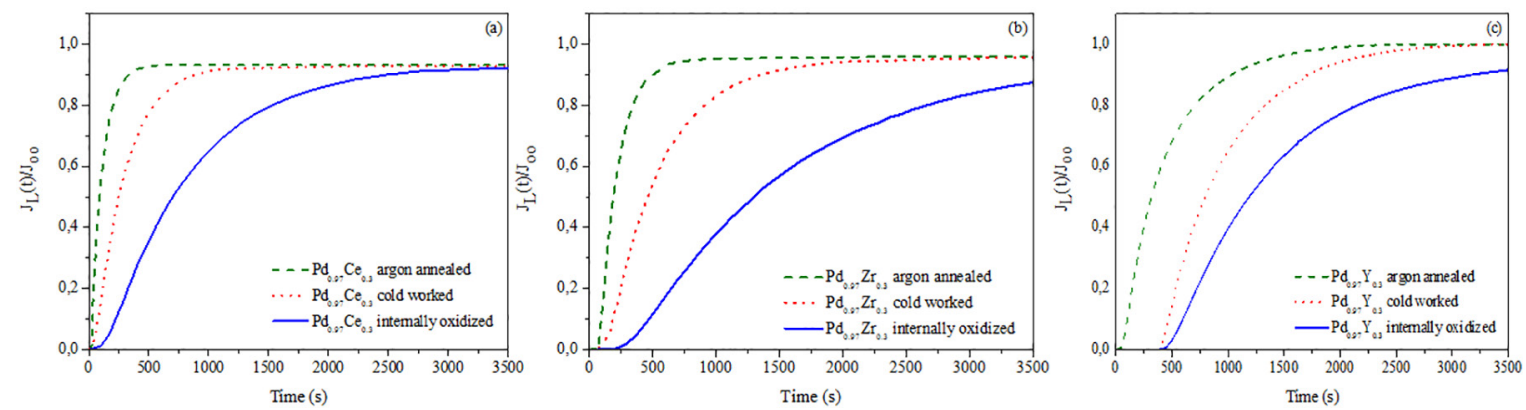

Figure 8. Hydrogen permeation curves with $1.0 \mathrm{~mA}: \mathrm{Pd}_{0.97} \mathrm{Ce}_{0.03}$ (a); $\mathrm{Pd}_{0.97} \mathrm{Zr}_{0.03}$ (b) and $\mathrm{Pd}_{0.97} \mathrm{Y}_{0.03}$ (c). 
oxidized condition. This behavior can be explained on the basis of the shape, size and location of the oxides precipitated in each alloy ${ }^{8,11}$. Ytrium and zirconium oxides have almost similar size, but different shape, spherical for Y oxide, and near square for $\mathrm{Zr}$ oxide. In addition, $\mathrm{Zr}$ oxides precipitate preferably at grain boundaries, while $\mathrm{Y}$ ones are more dispersed in the matrix. Despite of these differences, the $\mathrm{Y}$ and $\mathrm{Zr}$ oxides seem to produce similar effects on the $\mathrm{H}$ diffusivity, because the $\mathrm{D}_{\text {app }}$ of $\mathrm{Pd}_{0.97} \mathrm{Y}_{0.03} \mathrm{IO}\left(2.5 \times 10^{-12} \mathrm{~m}^{2} . \mathrm{s}^{-}\right.$ $\left.{ }^{1}\right)$ and $\mathrm{Pd}_{0.97} \mathrm{Zr}_{0.03} \mathrm{IO}\left(3.0 \times 10^{-12} \mathrm{~m}^{2} . \mathrm{s}^{-1}\right)$ alloys are very close. On the other hand, the Ce oxide precipitated in $\mathrm{Pd}_{0.97} \mathrm{Ce}_{0.03}$ IO alloy, with the acicular shape shown in Figs. 4(a-b), has a less effective trapping effect $\left(\mathrm{D}_{\text {app }}=6.0 \times 10^{-12} \mathrm{~m}^{2} . \mathrm{s}^{-1}\right)$.

Moreover, the solubility has an inverse behavior in comparison with the diffusivity for all cases discussed (Table 1). It is observed that IO is the condition that maximizes the amount of stored hydrogen, followed by $\mathrm{CW}$ one. This raise occurs because the oxide matrix interface has higher binding energy than dislocations, so that it is probably an irreversible trap that enabling, this way, higher solubility.

Hydrogen release and detrapping from the metals, during heating processes were studied by means of thermal desorption spectroscopy (TDS). Typical TDS curves (for the heating rate $10^{\circ} \mathrm{C} / \mathrm{min}$ ) for all three conditions of studied $\mathrm{Pd}_{0.97} \mathrm{Y}_{0.03}$ alloys can be compared with Pd CW in Figure 9. Differences in the microstructure of the studied condition noticeably influence the shape and height of the observed TDS peaks, as well as the temperature of the peaks.

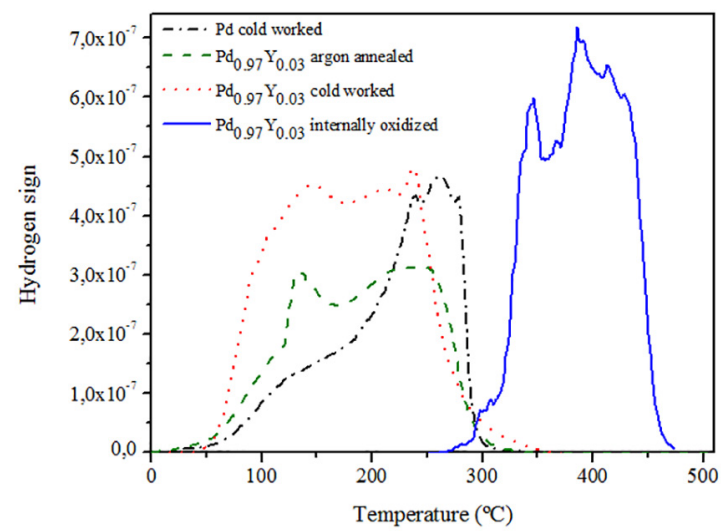

Figure 9. TDS spectra for hydrogen release from $\mathrm{Pd}_{0.97} \mathrm{Y}_{0.03}$ alloys.

The TDS spectrum, measured for $\mathrm{Pd} \mathrm{CW}$ revealed three well-defined peaks at 238,261 and $278^{\circ} \mathrm{C}$. Kirchheim ${ }^{12}$ and co-workers reported that hydrogen desorption occurs from: octahedral sites, reversible and irreversible trappings, in that order, as the temperature increasing. So that, this peaks in palladium could be attributed to diffusible hydrogen, dislocations and hydrides. $\mathrm{As}^{\mathrm{Pd}_{0.97}} \mathrm{Y}_{0.03} \mathrm{CW}$ samples exhibit similar TDS spectrum to $\mathrm{Pd} C \mathrm{CW}$, their peaks can be characterized in the same way.
Nevertheless for AA condition, there are only two peaks, located at 137 and $246^{\circ} \mathrm{C}$. The missing peak corresponds to dislocations, because heat treatment annihilates the most of them. Analysis of TDS spectra for $\mathrm{Pd}_{0.97} \mathrm{Y}_{0.03} \mathrm{IO}$, reveals at least four well-defined peaks at $303,347,386$ and $412^{\circ} \mathrm{C}$. This more complex format is probably due to yttrium oxides precipitated in grain boundaries and dispersed in the matrix.

The displacement of the temperature peaks between IO and the other conditions ratifies the irreversible nature of the oxides in hydrogen trapping. TDS graphic presents similar shapes for $\mathrm{Pd}_{0.97} \mathrm{Y}_{0.03} \mathrm{AA}, \mathrm{CW}$ and $\mathrm{Pd} \mathrm{CW}$, because of reversible hydrogen trapping on dislocations and impurity atoms. CW samples have curves with higher height peaks than argon annealed condition. This occur owing combined effect of dislocations and substitutional atoms or hydride formation.

\section{Summary and Conclusions}

This study aimed to investigate the influence of the different microstructures, such as: substitutional atoms, dislocations and nanoxides with different morphologies. Thus, the results found can be summarized as follows:

- Air heat treatment at $800^{\circ} \mathrm{C}$ for $24 \mathrm{~h}$ promotes internally oxidation of $\mathrm{Ce}, \mathrm{Zr}$ and $\mathrm{Y}$ leading to nanoxides precipitates. Cerium and zirconium oxides have similar stoichiometry but the morphology of the first one is fine acicular. Both are coherent with the palladium matrix. While the oxides of $\mathrm{Y}$ and $\mathrm{Zr}$ have almost the same size and resembling shapes.

- Cerium is the element that lowers the most the diffusivity of hydrogen whereas yttrium lead to the highest one for argon annealed condition. Nevertheless all values are smaller when compared with pure Pd.

- The oxide precipitation induces a significant increase in hydrogen storage. Alloys with yttrium nanoxides present the highest solubility, followed by $\mathrm{ZrO}_{2}$ and $\mathrm{CeO}_{2}$. This behavior can be explained based on the shape, size and distribution of the oxides. Yttrium oxide has the lowest diffusion coefficient, due to its morphology (the smallest spherical nanoxide). - TDS curves for cold worked (CW) and argon annealed (AA) have similar shape and present near temperature range. However internally oxidized (IO) spectra has a more complex format with higher temperatures.

- Nanoxides are irreversible traps that improve hydrogen stored on palladium alloys. Dislocations and impurity atoms on solid solution have little binding energy that detraps hydrogen at smaller temperatures. 


\section{Acknowledgements}

Authors acknowledge the financial support of Brazilian Research Agencies: CAPES, CNPq and FAPERJ.

\section{References}

1. Gesari SB, Prosanto ME, Juan A. Simulation of hydrogen trapping at defects in Pd. International Journal of Hydrogen Energy. 2009;34(8):3511-3518.

2. Iwaoka H, Arita M, Horita Z. Hydrogen diffusion in ultrafinegrained palladium: Roles of dislocations and grain boundaries. Acta Materialia. 2016;107:168-177.

3. Michler T, Balogh MP. Hydrogen environment embrittlement of an ODS RAF steel - Role of irreversible hydrogen trap sites. International Journal of Hydrogen Energy. 2010;35(18):97469754.

4. Jose D, Jagirdar BR. Nature of hydrogen atom trapped inside palladium lattice. International Journal of Hydrogen Energy. 2010;35(13):6804-6811.

5. Zhang W, Luo S, Wang D, Flanagan TB, Balasubramaniam R. Hydrogen segregation to internal interfaces of Pd-yttria composite prepared by internal oxidation of Pd-Y alloys. Journal of Alloys and Compounds. 2002;330-332:607-611.
6. Azambuja VM, Dos Santos DS, Pontonnier L, Morales M, Fruchart D. Study of an internally-oxidized $\mathrm{Pd}_{0.97} \mathrm{Ce}_{0.03}$ alloy. Scripta Materialia. 2006;54(10):1779-1783.

7. Dos Santos DS, de Miranda PEV. The use of electrochemical hydrogen permeation techniques to detect hydride phase separation in amorphous metallic alloys. Journal of NonCrystalline Solids. 1998;232-234:133-139.

8. Balasubramaniam R, Noh H, Flanagan TB, Sakamoto Y. Hydrogen solubility in $\mathrm{Pd} / \mathrm{Al}_{2} \mathrm{O}_{3}$ composites prepared by internal oxidation of Pd-Al alloys. Acta Materialia. 1997;45(4):1725-1733.

9. Kirchheim R, McLellan RB. Diffusivity of hydrogen in dilute alloys of copper and niobium in palladium. Acta Metallurgica. 1982;28(11):1549-1554.

10. Cao Y, Li HL, Szpunar JA, Shmayda W. Modeling of hydrogen trapping in the deformed $\mathrm{Pd}$ and $\mathrm{Pd}_{77} \mathrm{Ag}_{23}$ alloy. Materials Science and Engineering: A. 2004;379(1-2):173-180.

11. Gouthama G, Balasubramaniam R, Wang D, Flanagan TB. Transmission electron microscopy of hydrogen effects in internally oxidized palladium-chromium alloys. Journal of Alloys and Compounds. 2005;406(4-6):617-620.

12. Huang XY, Mader W, Kirchheim R. Hydrogen and oxygen at metal/oxide interfaces. Acta Metallurgica et Materialia. 1991;39(5):893-907. 